\title{
Pulmonary Artery Diastolic Pressure
}

National Cancer Institute

\section{Source}

National Cancer Institute. Pulmonary Artery Diastolic Pressure. NCI Thesaurus. Code C120941.

The blood pressure in the pulmonary artery during ventricular relaxation (diastole). 